\title{
CADERNO DE RESUMOS
}

\section{JORNADA NACIONAL DE ESTUDOS EM EDUCAÇÃO PERFORMATIVA, LINGUAGEM E TEATRALIDADES (ELITe/UFPR/CNPq)}

e

Encontro dos Grupos de Pesquisa Contextos de Educação da Criança e Cultura Escola e Educação Criadora (UNIVALI/CNPq)

\section{Mesas Temáticas}

\author{
Organização: \\ Prof. Dr. Jean Carlos Gonçalves \\ Prof. Dra. Michelle Bocchi Gonçalves \\ Profa. Dra. Valéria Silva Ferreira \\ UNIVALI - Itajaí - SC \\ 19 de setembro de 2018
}




\section{A JORNADA}

A II Jornada Nacional de estudos em Educação Performativa, Linguagem e Teatralidades (ELiTe/UFPR/CNPq, realizada na UNIVALI - Itajaí/SC em 19/09/2018 reúniu pesquisadores das seguintes universidades: UFPR, UNIVALI, UNESPAR, FURB e UDESC. Em 2017 a Jornada aconteceu na UNICSUL (Campus Anália Franco - São Paulo), no formato de comunicações orais, tendo como conferencista de abertura a prof. Beth Brait (PUC-SP). Para 2018, o ELiTe/UFPR/CNPq, em parceria com os grupos de pesquisa Contextos de Educação da Criança e Cultura, Escola e Educação Criadora (UNIVALI/CNPq), propôs três mesas temáticas com professores convidados, uma roda de conversa sobre as pesquisas em andamento no grupo (open space) e um espetáculo teatral (A Serpente - Carmen Group). A conferência de abertura foi ministrada pela professora Dra. Angela Chaverra Brand (Faculdade de Artes/UDEA - Colômbia). 


\section{O ELiTe/UFPR/CNPq}

O Grupo de Pesquisa ELiTe - Laboratório de Estudos em Educação performativa, Linguagem e Teatralidades, liderado pelos professores Dr. Jean Gonçalves e Dra. Michelle Bocchi Gonçalves, reúne pesquisadores do campo da educação performativa, dos estudos da linguagem e das teatralidades contemporâneas. Reúne atualmente membros e colaboradores do Brasil (Paraná, Santa Catarina, São Paulo e Acre) e do exterior (França, Inglaterra, Portugal e Colômbia). As sete linhas de pesquisa do ELiTe correspondem ao aporte teórico-metodológico de seus pesquisadores, colaboradores e estudantes, o que resulta em um amplo espectro de investigações nas áreas correlacionadas nos contextos de graduação e pós-graduação (Mestrado, Doutorado e Pós-Doutorado). Os resultados tem sido apresentados à comunidade na forma de artigos científicos, capítulos de livro, comunicações de pesquisa, participação em eventos nacionais e internacionais, elaborações de relatórios de pesquisa, dissertações e teses, seminários, mostras de processos de treinamento corporal e espetáculos teatrais. 


\section{Grupo de Pesquisa: Contextos da Educação da Criança (UNIVALI/CNPq)}

Objetiva compreender os diferentes contextos nos quais as crianças estão sendo educadas. Analisar e descrever as relações, rupturas, acontecimentos, continuidades e descontinuidades que aí se originam nos discursos e práticas. Desta forma estudamos os contextos das políticas de infância e de educação, os contextos da formação e prática docente, contextos da educação infantil e anos iniciais e seus elementos constitutivos.

Relação família e escola

Políticas de formação docente

Relação políticas educacionais e prática docente

Intencionalidades docentes

Políticas de Currículo para Educação Infantil

Líder do grupo: Profạ. Dra. Valéria Silva Ferreira

\section{Grupo de Pesquisa: Cultura, Escola e Educação Criadora (UNIVALI/CNPq)}

Este grupo de pesquisa tem por objetivo investigar como a cultura, em especial a arte e a estética, contribui para o desenvolvimento pessoal e profissional do sujeito. Os projetos de pesquisa estão direcionados para discussões que envolvem as áreas Literatura, Artes Visuais, Teatro, Cinema, Dança e Música, com o intuito de discutir a natureza do conhecimento sensível e sua interferência principalmente na constituição do discente e docente. Os temas para orientação de pesquisa são:

Formação de professores de artes

Currículo de artes

Mediação cultural

Formação estética

Espaços formais e não formais de ensino de arte

Formação de leitores

Líder do Grupo: Adair de Aguiar Neitzel

Revista "O Teatro Transcende" Departamento de Artes - CCEAL da FURB - ISSN 2236-6644 Blumenau, Vol. 24, № 1, p. 04 -17- (2019)

Edição Especial -JORNADA 


\title{
CONFERÊNCIA DE ABERTURA
}

\author{
ARTE Y ACONTECIMIENTO \\ CASO EL CUERPO HABLA
}

Angela María Chaverra Brand Universidade de Antioquia - UDEA - Colômbia

\begin{abstract}
El trabajo que se presenta, da cuenta de un trayecto que se generó en la pregunta por el cuerpo, el arte y la ciudad en la contemporaneidad, lo que desencadenó en el encuentro con la disolución del cuerpo de la identidad y el aparecer de la carne suculenta, el cuerpo sin órganos como lo propone Artaud; la paradoja de una representación duplicada que, como lo expone Foucault, quiebra las estructuras por las que se rige la obra de arte en la actualidad, para devenir en un acontecimiento, una presencia; la alianza de las prácticas artísticas con maneras de re-existencia para crear actos de fabulación; la ruptura de los espacios convencionales del arte que se evidencia en el asalto a las calles y escenarios no convencionales; el intento de rasgar ciertos límites impuestos por las artes clásicas para atravesar sus fronteras, problematizar la relación del arte con las ciencias sociales, diseñar estrategias pedagógicas e insertar temas cotidianos, sociales, políticos, ecológicos y estéticos. El hecho de la carne, a través de un dispositivo como la performance, muestra otro horizonte, un giro que no sólo toca las artes plásticas sino al teatro, la danza, la música e integra todo un universo de posibilidades.
\end{abstract}




\section{Mesa Temática I - Educação e Estética}

\section{A estética na educação da criança pequena}

Prof. Dra. Marynelma Camargo Garanhani Universidade Federal do Paraná - UFPR

Qual estética na educação da criança? Com esta indagação apresento reflexões e ideias sobre a educação da criança pequena como uma experiência estética, com base em estudos da Sociologia do Corpo de Le Breton e o princípio estético na obra de Loris Magaluzzi da Pedagogia Italiana de Reggio Emilia.

Palavras-chave: Criança; Experiência; Estética. 


\section{Grupo de Pesquisa Cultura, Escola e Educação Criadora}

Prof. Dra. Adair de Aguiar Neitzel

Prof. Dra. Mônica Zewe Uriart Universidade do Vale do Itajaí -UNIVALI

O GP "Cultura, escola e educação criadora", desde a sua criação em 2000, se propôs a desenvolver pesquisas que envolvem as artes na formação humana, tendo sempre a clareza de que não basta falarmos de arte, é preciso respirar arte. $\mathrm{E}$ também discutimos em nossos encontros que não se trata de pensar a arte na educação mas de educar-se na arte porque se nós, professores, somos consumidores de arte, se mantemos com ela uma relação de fruição, se tivermos uma educação estética, nos colocaremos em um movimento estésico que nos oportunizará experiências no sentido atribuído por Larrosa e Heidegger. A dinâmica dos nossos encontros envolve vivências estéticas, estudos de aprofundamento e apresentação das pesquisas em andamento. $O$ Grupo possui 5 livros publicados, nos quais orientandos, orientadores e convidados divulgam suas pesquisas e, nos últimos 8 anos, a publicação dos orientandos atingiu 29 artigos em periódicos e 42 capítulos de livros. Nossas pesquisas trabalham com os conceitos de Educação Estética e Mediação Cultural. Entre as metodologias mais utilizadas citamos a Análise de Conteúdo, Narrativas, Reversibilidade, Cartografia e PEBA. Anualmente são oferecidos seminários aos mestrandos e doutorandos, com temas que envolvem Literatura, Música, Artes Visuais e Filosofia.

Palavras-chave: Grupo de Pesquisa; Educação Estética; Mediação Cultural. 


\section{Mesa Temática II - Educação, Linguagem e Performance}

\section{"Eu preciso ser outro"}

Prof. Dra. Otilia Lizete de Oliveira Martins Heinig Universidade Regional de Blumenau - FURB

As relações entre linguagem, educação e performance são o foco desta mesa temática. O objetivo aqui é refletir sobre a construção de imagens do locutor, interlocutor e referente para produção de sentidos. O viés teórico, na perspectiva bakhtiniana, se volta para o exame de textos e discursos; dialogia e alteridade. Foram selecionados 4 enunciados concretos para a análise: duas capas de revista, uma de livro e uma propaganda a fim de discutir o papel do texto nas ciências humanas e relacionar com a educação. As análises dos textos multissemióticos permitem dialogar com a perspectiva enunciativa, pois se depreendem aspectos como: intenção discursiva, expressão valorativa, atitude responsiva ativa, direcionamento do enunciado e excedente de visão. Possíveis considerações podem ser feitam a partir do diálogo com os enunciados. O outro é fundamental para o direcionamento do texto; os sentidos são construídos também pelo interlocutor; o eu no mundo vê o mundo do seu ponto de vista, mas o faz parcialmente e fora de si; os gêneros do discurso sofrem mudanças com o tempo apontando para a compreensão de memória. Finalmente, a escola precisa dialogar com as diferentes linguagens a fim de levar os alunos a construírem conhecimento sobre os gêneros e suas dimensões.

Palavras-chave: Linguagem; Educação; Alteridade. 


\title{
Corpo e Educação Performativa: Teias Discursivas
}

\author{
Prof. Dra. Michelle Bocchi Gonçalves \\ Universidade Federal do Paraná - UFPR \\ Universidade do Vale do Itajaí - UNIVALI (PNPD/CAPES)
}

A presente comunicação pretende discutir as relações entre corpo e educação performativa a partir de uma perspectiva discursiva. Tomando como base teórica os Estudos da Performance na Educação, busca-se abordar a questão do corpo em contextos educacionais, investigando um conjunto de aspectos que possam mobilizar pressupostos para a noção de corpo ideológico como centralidade. Para a análise e discussão, apresenta-se um vídeo produzido por professores em formação na Licenciatura em Educação do Campo (UFPR Litoral), revisitado pela ótica da Análise do Discurso de Linha Francesa. Os resultados apontam, a partir da proposição de caminhos de pesquisa para uma educação performativa, possibilidades de (re)significação dos sentidos de escola, o que reverbera na prática educativa dos docentes pesquisados e na forma como concebem, hoje, uma educação capaz de dar ao estudante espaço para resistência e diálogo, no qual os corpos, na educação, possam escapar do lugar comum de menosprezo e invisibilidade.

Palavra-Chave: Corpo; Educação Performativa; Análise do Discurso. 


\title{
Sentidos de “protagonismo" na BNCC do Ensino Médio
}

\author{
Cláudia Garcia Cavalcante \\ Universidade Federal do Paraná - UFPR
}

Esta comunicação parte de um recorte de artigo no prelo: Protagonismo teatral e protagonismo educacional: quais deslocamentos fazem surgir um a(u)tor?. Aquele oportunizou um diálogo entre os sentidos de "protagonismo", nos campos teatral e educacional, a partir dos estudos de Bakhtin e o Círculo. Este analisa enunciados presentes no texto da Base Nacional Comum Curricular do Ensino Médio (2017), considerando os sentidos emergentes da palavra "protagonismo", a fim de estabelecer possíveis pontos de contato com a categoria bakhtiniana de autoria. Ao resgatar as cadeias discursivas da esfera educacional em particular, a análise permitiu compreender que essa apropriação pela BNCC-EM assume uma nova dimensão discursiva, descaracterizando seus enunciadores e interlocutores originais e não oferecendo subsídios para a construção do protagonismo/autoria. Além disso, evoca um sujeito estudante passivo, refém das determinações do documento que impacta nas ações da escola.

Palavras-chave: Análise dialógica do discurso; Autoria; Protagonismo 


\title{
Mesa Temática II - Educação e Teatralidades
}

\author{
Teatro e Leitura - ação escola
}

Prof. Dra. Heloise Baurich Vidor Universidade do Estado de Santa Catarina - UDESC

Resumo: Essa comunicação abordará uma ação vinculada ao projeto de pesquisa Teatro, Leitura, Literatura e Educação: encontro com o texto, desenvolvido no Departamento de Artes Cênicas da Universidade do Estado de Santa Catarina (UDESC), da qual a autora é professora adjunta. A partir do estudo da obra dos autores Jan Masschelein e Maarten Simons, Jorge Larrosa e Daniel Pennac, a docente propõe a criação do espetáculo Coro dos Maus Alunos, com estudantes da Licenciatura em Teatro, cujo texto tem como tema a escola, as relações de poder e as tensões inerentes ao ambiente escolar que envolvem professores, alunos, diretores, pais na esfera das relações humanas e institucionais. Trabalhando aspectos de encenação como a coralidade e os objetos tipicamente "escolares", a encenação pretende dialogar com o universo adolescente na escola, retratando estes maus alunos com a complexidade latente que o tema evoca nos tempos atuais. A condução do processo de criação do espetáculo teve como perspectiva a aproximação da universidade e da escola básica, que nesse caso aconteceu com os professores de teatro e alunos da E. E. M. Professora Maria da Gloria Viríssimo de Farias, da cidade de Biguaçu/SC, e a criação de um espaço em que os estudantes da universidade, futuros professores, ao mesmo tempo que se preocupassem com os aspectos da atuação e da montagem de um espetáculo, se detivessem nas questões que envolvem o ofício do professor e a escola.

Palavras-chave: Montagem Teatral; Obra-aula; Formação do professor 


\section{Educação e(m) Artes do Corpo}

Prof. Dra. Cristiane Wosniak

Universidade Estadual do Paraná

A participação da artista-docente-pesquisadora Cristiane Wosniak na mesaredonda (3) Educação e Teatralidades, propõe algumas reflexões metodológicas sobre as práticas educativas singulares - artes do corpo na/para a cena - aplicadas no âmbito do Curso de Dança Moderna da UFPR (CDM) que, desde 1990, configura-se como um curso extensionista, gratuito e aberto à comunidade em geral, a partir dos 7 anos de idade. Parte-se do princípio de que este curso, pioneiro em instituições públicas federais, pode ser considerado um modelo institucional escolar de formação peculiar para os sujeitos da aprendizagem artística/em dança. A partir da inserção da pesquisadora no GP ELiTe (linha de pesquisa: Teatralidades, Artes do Corpo e Estudos da Performance na Educação), o foco da investigação particularizada recai sobre o panorama contextual da criação do CDM. Pretende-se apresentar, em linhas gerais, a provável inserção do objeto de pesquisa no estatuto ou formato de uma instituição escolar curitibana, cujas práticas educativas de cunho artístico contribuíram para a formação de bailarinos e bailarinas paranaenses em larga escala numérica. Em cena: corpo, dança, técnica, história e estudos da performance/encenação na Educação.

Palavras-chave: Artes do corpo; Dança; Instituição escolar; Práticas educativas singulares; Curso de Dança Moderna da UFPR. 
Teatro e Educação: o estágio docente e o discurso pessoal dos sujeitos

Prof. Msc. Caroline Carvalho Universidade Regional de Blumenau - FURB

Tem-se no estágio docente o momento em que o acadêmico toma contato com o sujeito que aprende, tem-se no estágio também o olhar sensível às necessidades do espaço escolar, e a percepção de que o corpo do sujeito aprende, apreende e constrói relações. De nossas incursões às escolas tomounos de sobressalto a experiência de nos relacionarmos com uma Escola Rural, espaço em que as crianças nunca haviam tomado contato com o teatro, e que neste encontro se fez possibilidade. O Teatro assim, em relação com a comunidade rural, veio-nos como uma possibilidade de encontro, com a prática teatral e com o discurso pessoal de cada sujeito. Instigados pela pesquisa realizada pelo francês Phillipe Meirieu em 1992 aventuramo-nos a solicitar a estes sujeitos que nos contassem a sua história, e surpreendemo-nos com a relação de curiosidade e necessidade instaurada neste encontro. Curiosidade latente, de quem jamais teve a oportunidade de vivenciar o ensino de teatro, $\mathrm{e}$ a necessidade de colocar-se na cena, ao contrário do que imaginávamos, o que nos esperava eram sujeitos com desejo de colocar seus corpos em movimento, narrando-nos sua história pessoal e em relação a sua comunidade, construindo uma preciosa relação dialógica entre alunos docentes e sujeitos que apreendem.

Palavras-chave: Teatro; Estágio docente; Comunidade. 


\section{Lançamento: Dossiê - Teatralidade, Performance e Educação}

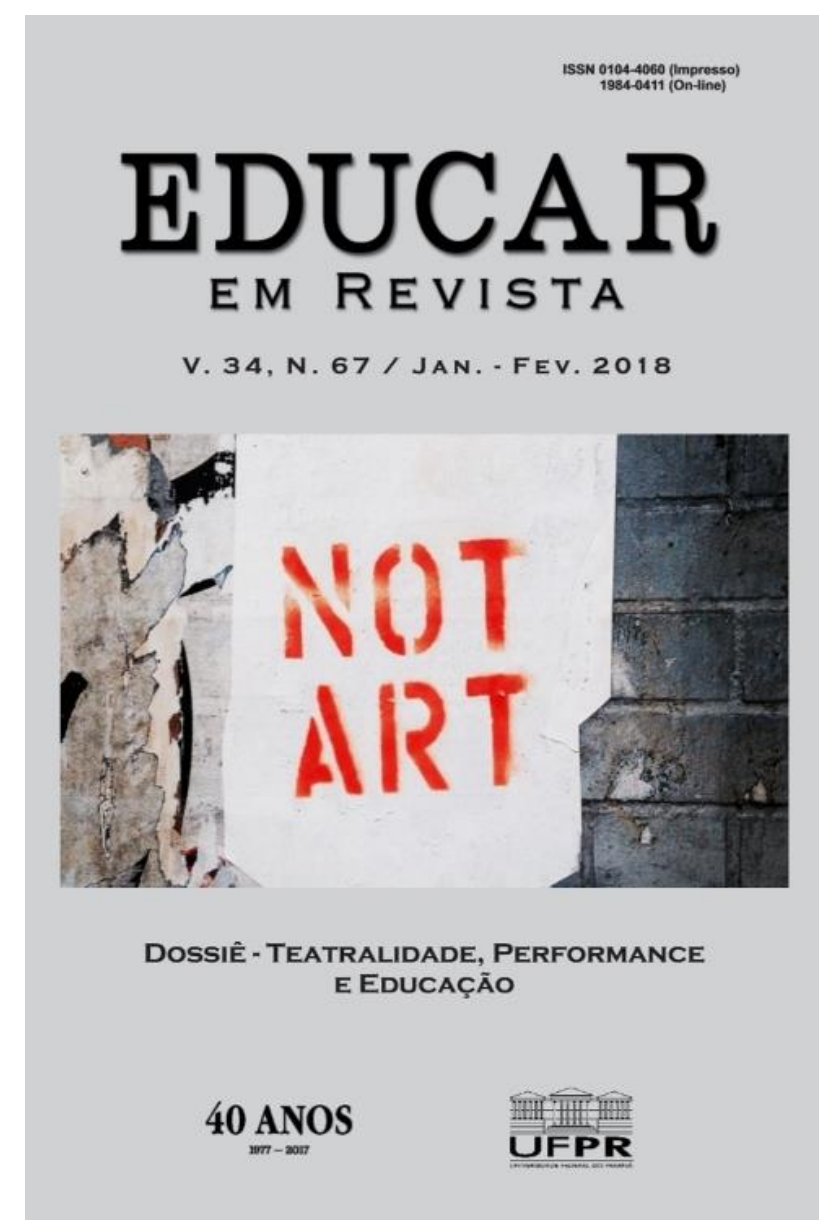

Disponível em: http://www.scielo.br/scielo.php?script=sci issuetoc\&pid=0104406020180001\&lng=en\&nrm=iso 